\title{
Communication between Teachers and Parents using the WhatsApp Application
}

\author{
Egoza Wasserman \\ Herzog Academic College \\ Jerusalem, Israel \\ Yaffa Zwebner \\ Elementary School, Gilo \\ Jerusalem, Israel
}

\begin{abstract}
The purpose of this research is to examine how the electronic media, WhatsApp, effects the communication between teachers and parents and the teacher's work. The research was conducted in the qualitative method using an interpretive constructivist paradigm with twelve teachers who use the WhatsApp media. Three main categories were discovered from the analysis of the interviews: management of the group which includes who is responsible for managing the group and group time limitations, content of the WhatsApp which includes material and technical content and the positive and negative effects of using WhatsApp on the teachers. It can be concluded that the use of WhatsApp is necessary and beneficial to the teacher's work, but the boundaries must be examined and defined in the use of the WhatsApp groups.
\end{abstract}

Keywords: WhatsApp Application, parent teacher relationships, technology

\section{Introduction}

Communication between parents and teachers is referred to in the research literature as "parental involvement". The concept of "parental involvement" is a comprehensive name for the many and varied activities carried out by parents with their children or with other significant persons related to the lives of their children. In the context of parental involvement in school, the intention is the reciprocal relationship between the parents and the educational establishment, with regard to school work and the educational process (Fischer, 2010). This involvement is anchored in law and is based on the parents' right to influence their children's education. This involvement is reflected both in the technical and organizational spheres and in the educational process (Friedman \& Fischer, 2002). 
Parental involvement occurs in a positive manner when there is continuous and efficient communication between the parents and the teachers (HooverDempsey \& Whitaker, 2010; Taft, Schlein, \& Ramsay, 2016; Kraft, \& Rogers, 2015). In order to create this effective connection between teachers and parents, the teacher needs to communicate with the parents and encourage them to be involved both in the school activities and the education of their children (Ho, Hung \& Chen, 2013). In addition, the research indicates that parental involvement has a significant impact on the student's achievements (Hakyemez, 2015; Hamlin \& Flessa, 2016; Jeynes, 2016).

In the past few years, with the expansion in the use of new media and information technologies, there has been an increase in communication channels between teachers and parents. New media channels such as computers or smart phones based on the internet. Also: e-mail (Thompson, 2008; Thompson, 2009), social networks (Karapanos, Teixeira \& Gouveia, 2016), SMS messages and Instagram. Because these new media channels allow direct messaging from everywhere and at any time - their use significantly increases mutual availability between the parents and the teachers (Schectman \& Boucherian, 2015; Jacobson, 2003).

The online environment therefore offers a variety of media channels, each of which has its own unique characteristics (Witztum, 2014). This variety allows teachers to choose the environment best suited to their needs. Kurtz's research showed that e-mail is the most common media channel used by parents to teachers (Kurtz, 2014). Other new channels are social networks like Facebook, WhatsApp (used for sending immediate messages, photos and video clips), twitter and more. Social network is a general term for web environments that include a variety of online tools to create and save connections between surfers 24 hours a day. The world of the social media is a world of "here and now" they look, respond, exist (Kurtz, 2014). A large part of the communication between parents and teachers is via social networks in general and instant messages in particular, using smart phones, where there is wide use of WhatsApp and little use of Facebook (Schectman \& Boucherian, 2015).

Findings from various studies on e-mail communication raise four main topics discussed in correspondence between parents and educators: student achievement, schedule issues, health and mental well-being, and behavior issues in the educational system (Kosaretskii \& Chernyshova, 2013). In addition, parents who transmit messages through these media channels are provided with greater access to the teacher at all times and use this to transmit personal information about their child or to clarify general school matters (Olmstead, 2013).

The electronic media, which has greatly increased the connection between parents and teachers, has many advantages stemming from the very empowerment and ease of use, but there are also disadvantages in the use of these means, both in terms of context and characteristics of the media. 


\section{Advantages of using electronic media between parents and teachers}

A central component of involvement is the frequency of communication that exists between the parent and the teacher and its depth. The use of new media technology creates new opportunities to communicate between parents and teacher mainly by increasing the access of the parent to the teacher (Schectman \& Boucherian, 2015). Mobile devices, especially smart phones, change the "rules of the game" in the frequency of conversation between parent and teacher, in its form as both a personal conversation and as a group conversation, in its visual representation and especially in the fact that school matters accompany the owners of smartphones - teachers and parents alike - everywhere, at any time and non-stop.

Therefore, technology is perceived as shaping the patterns of discourse between teachers and parents and providing greater involvement of the parents. (Kurtz, 2014). In addition, the use of media influences the depth of involvement of the parents by increasing the sense of partnership between the parents and the teacher (Starhovsky et al., 2008). It may bring the two sides closer together and creates a healthy partnership based on mutual trust. In addition, the use of media was found to be effective in the lessening of interpersonal tension between the two sides and consequently to the increase of the parent's satisfaction. The interaction between the parents and the educational establishment is characterized by a lack of clarity and conflict. Parents do not always know what their role is and the school system does not know the parents' expectations. In this context, Kosaretskii and Chernyshov (2013) found that the frequency of electronic media has a tangible effect on the parental involvement. The informal dialogue contributes to reducing interpersonal tensions and encourages positive attitudes and involvement of the parents in the school. Moreover, the new media channels allow easy and effective involvement which enables fast and efficient two-way communication. Olmstead (2013) found that both the parents and the teachers indicated that technology optimizes communication between them, shortens response time and therefore increases parental involvement in the school and greatly influences the pupil's achievements.

\section{Disadvantages of using electric media between parents and teachers}

The use of various types of electronic media might damage the correct parental involvement in the school (Keley-Shahin \& Gefen, 2014). A significant difficulty is the over-involvement of the parents in what is happening in the school. Setting boundaries on parents' involvement in what is going on in school is discussed at great length in the literature. The issue of the boundaries that the teacher is supposed to present to parents regarding school policy revolves around the agreements and protocols that are made while coordinating initial expectations (Fisher, 2010). In his research, Kurtz (2014) found that the teachers expressed concern that as a result of the availability of access to the teacher and information, the involvement of the parent would become intervention. Another negative result of new electronic media is the illusion of friendship and connection between parents and teachers and between parents of other pupils. 
This illusion is created mainly from the use of WhatsApp groups. But aside from the technical connection there is no deeper relationship formed with the rest of the parents in the group. Also, the use of new media channels during school activities like sending photos or video clips in real time can evoke a false sense of being part of the activity (Schectman \& Boucherian, 2015).

As a result of this Schectman and Boucherian, (2015) warn that it is important to reiterate to the teachers and parents that there is no substitute for face-to-face communication which enables a close relationship and they should continue to meet in order to create trust and professional working relationships between parents and educators. Another consequence of the new media is the blurring of the boundary between the home space and the classroom space. Blurring of boundaries means sending private messages that include personal and intimate information to the public. Kurt's research (2014) revealed that quite a few parents claimed that using the media of Facebook creates a problem of boundaries. A group that aims to serve as a professional means of communication between parents and teachers can very easily become a social group.

Using new media has the effect of neutralizing status symbols of the users. The significance of this is that the communication is devoid of social and cultural differences between the users including the levels of social hierarchy. This kind of communication "deposes" the positions of authority and changes the communication to one between equals. This can lead to communication characterized by conflict and even aggression and insults. Egalitarianism expressed in reducing the hierarchical model may also impair its efficiency. For example, a parent can see himself free to address any subject directly to the supervisor of the school. This direct contact, without prior contact with the teacher, is liable to impair the effectiveness of the parent-teacher communication (Shechtman \& Busherian, 2015).

In addition there exists disadvantages in the use of the new media that involve interaction between the parent and teacher. An overload of information, the overload of information which results when every parent responds to every message causes the parent to filter the messages and to the possibility of filtering out important information (Kurtz, 2014).

Incorrect interpretation of the message, misunderstandings occur when the message is not interpreted correctly, for example when the parent interprets the message as being too angry or as less important than it is in reality (Shechtman \& Busherian, 2015). Disparaging remarks about the teacher in front of all the parents, many times the use of new media channels cause the teacher to experience insults and contempt from the parents (Fischer, 2010). The reactions of the parents during the mutual interaction can sometimes relay to the teacher a lack of appreciation by the parents for their work in the school. And the general population's lack of access to new media channels, this communication is not being used by the entire population due to the limitations of connection, speed, lack of technology skills or low socio-economic backgrounds. Or they do not own smart phones because of religious beliefs or economic constraints (Shechtman \& Busherian, 2015). 


\section{Purpose of the Study}

We can see from this that electronic communications has a wide influence in the measure of parental involvement in the school, and the advantages and disadvantages involved. In view of the ever increasing growth of electronic media for use by parents and teachers, the question arises how the electronic media affects the communication between parents and teachers and the amount of parental involvement in the school. And because this application is the most accessible and available communication channel among teachers and parents, the research focuses on the WhatsApp phenomenon. The purpose of this research is to examine how electronic media, specifically WhatsApp, influences the connection between parents and teachers and its effect on the teacher's work.

\section{Method}

\section{Research Method and Participants}

The research was conducted in the qualitative method using an interpretive constructivist paradigm. Twelve teachers participated from various primary schools in Israel. In these schools it is acceptable to use electronic media for sharing with the parents what is happening in the school. The teachers taught classes from first to sixth grade.

\section{Process and Research Tools}

The research tools were in-depth, semi-structured interviews, the teachers were asked questions relating to the use of WhatsApp. The questions were: why do you use WhatsApp? How has this media tool affected your work as a teacher? Are you pleased with the existence of this communication option? Etc. The interviews lasted between half an hour to one hour. The interviews were recorded and transcribed and later analyzed by Content Analysis where the transcripts were classified into categories with a common denominator. At the end of the proceeding, conclusions were drawn according to the different categories. The research was conducted after written permission was granted by the teachers. In addition, there were no identifying details about the schools according to the conditions requested by the participants of the research.

\section{Findings}

Three main categories were discovered from the analysis of the interviews: management of the group, content of the WhatsApp, The effects of using WhatsApp on the teachers. 


\section{Management of the Group}

All of the participants noted that they created WhatsApp groups and that they are the manager of the group. In addition, the participants say that they send most of the messages. As H said "I use it all the time, I am connected to 12 groups and I am quite active in some of them. You could say that I send most of the messages in those groups". Z added that sometimes the parents send the messages "there are some groups where the parents are the dominant ones and others where the teachers set the tone". In addition, the interviewees point out the need to limit the time schedule of the group's activities. Interviewee A suggests that the Ministry of Education limit the hours of sending messages. "I think there is a need to draw up a contract. A set of regulations regarding WhatsApp - from what hour to what hour you can send messages". Her remarks indicate that it is important to set rules to regulate the times of the group's activity. Teachers generally noted the importance of the need for procedures, noting that there are no formally written rules or customs.

\section{Content}

The interviewees noted that they use WhatsApp to communicate with the parents on a variety of subjects. The interviewee A pointed out that she uses WhatsApp for every kind of subject. "Everything! Today in the school where I work, simply put, there is no mouth, and every communication is written. Communication between parents and teachers and between teachers among themselves". In studying the examples that the interviewees gave, the content of the WhatsApp conversations can be divided into technical and essential topics.

The topics of discussion in WhatsApp concentrate on substantive issues. The interviewee A gives an example of a substantive issue: "in order to see what the learning situation is, to be in contact, etc." Conversations regarding the learning situation of the pupil has changed from a telephone call or personal meeting to a message on the WhatsApp. The interviewee $S$ claims that the teachers use the WhatsApp in order to remind the parents what the learning assignments are throughout the day. Thus the pupils feel that it is important to the teacher that they succeed and they progress in their learning. The pupil's success is defined by her as "giving power to the teacher": "I think this kind of communication has advanced us and given the teacher power...to repeat to the parents all the time and to remind them. I think it is very important to remind them all the time because today we are... overloaded with tasks, and the pupils are overloaded with work and television and games, but the teacher does not forget them. And the pupil thinks 'hey, the teacher has not forgotten me, it's important to her that I succeed'. It's enough even if we succeed with two children, to encourage them. I have become enslaved to the smart phone. I must write to them every day". We can see from this that the teacher is loading more responsibility on her shoulders to remind the parents about school assignments.

Some of the interviewees noted that they only use WhatsApp for technical topics. The interviewee B states: "most of the teachers who use WhatsApp use it to pass messages to the parents". The interviewee $\mathrm{Y}$ also cited examples of technical updates like: homework, absentee pupils: "at the end of the day sometimes I write 
which pupils were absent to update the parents if necessary". Another example: "to circulate an important message very very fast". From these examples we can see that teachers use WhatsApp for sending technical messages.

\section{The Effect of WhatsApp on the Teachers}

An examination of the interviews shows that communicating via WhatsApp influences the teacher. The following is a description of the positive effects vs. the adverse effects.

\section{Positive Effects}

Most of the interviewers stated that WhatsApp has a positive effect on their work as teachers, it is an easy and accessible form of communication. If in the past they had to send a written message home via the pupil and hope that it was received, today as soon as the message is sent by WhatsApp everyone is updated immediately. Like the Interviewee A noted: "in the past when I wanted to send a message to the parents I had to type an info memo and attach it to the communication notebook of every pupil in a class which numbered 40 pupils and hope that the parents would actually see the message. More than once, an important message did not reach parents for various reasons. Today all parents are with their smartphones all day and so the moment you send a message it is received by the parents. In the past I had a number of unpleasant experiences for the pupil where the parent did not receive the message about a festive meal and the pupil was very uncomfortable. With the introduction of WhatsApp I do not remember any incident like that. There is no doubt that this is a tremendous tool for transmitting information in the most accessible manner possible". From A's comments, we see that the use of WhatsApp made it easier for the teachers on the technical level. The interviewee $Y$ also described the advantages of sending messages by WhatsApp instead of writing a message. "All in all, it's a convenient thing. It's convenient that we can inform the parents with the click of a button and each parent will receive the message, instead of having relay it by broken telephone through the children, will they pass on the message, will they not pass on the message". Similar things were mentioned by B: "the speed, the immediate connection, the ability to share pictures during the school trip". Interviewee Y adds the topic of accessibility to events that occur in the classroom in real time. "The information is current and immediate. Which means when something happens in the classroom at the same instant you can update the parent of the child or all of the parents. Another example is planning a party, in just a few seconds you can know who will bring what to the party and the party is planned. As well as permission slips for school trips, etc". From these comments we can see that Interviewers can see the availability immediately. Another interviewee claims that the media gives teachers power that is reflected in the pupil's success. 


\section{Negative Effects}

Along with the advantages of WhatsApp media the interviewees cited negative effects of the media as well.

An analysis of interviews shows that the biggest disadvantage of the media in WhatsApp is the loss of control on the part of the teacher on the amount of messages that are sent. Thus a parent who opposes the teacher can drag other parents into the argument, according to the interviewee B "what happens is the teacher loses control of all the messages in the group. This can lead to a situation where the teacher sends a message, one of the parents gets angry and he agitates the other parents against the teacher and the teacher is powerless to stop it". The interviewee A states: "This reality of parents' opposition against stupid things becomes routine in every place where the media operates like this. Stories about teachers who have been hurt emotionally are numerous. I think that today every teacher working in the Ministry of Education can publish a book about the hurt he/she experienced from the parents ... " It can be said that sometimes the WhatsApp is used to send negative messages from the parents about the teachers instantaneously and without thought, and the teacher loses control of the media. Another disadvantage of this media is the removal of responsibility. When the teacher communicates with the parents on a daily basis, it remove all the burdens from the pupils of everything related to the studies, because the teacher will send the material via the WhatsApp anyway. In his words "another problem with this media is the removal of responsibility from the pupils concerning any school tasks. There are teachers who send the test material and the homework assignments via the WhatsApp, and this creates a situation where the pupils become devoid of responsibility and it is the parents who have to remember and tell them what to learn for the test". From this example it can be said that because of the WhatsApp the responsibility of the pupils for learning is reduced. Another aspect that is connected to negative consequences of WhatsApp use can be learned from the words of interviewee A who claims that this media violates the respect of the educational staff. In her words: "The big problem with this media is that it violates the distance and respect that the educational staff had previously. In the past a teacher was something to be respected. They used to say to me in certain situations "I' $m$ certain that this situation where parents feel they can write many things about the teacher which they would never have said to her face to face... The reality is that parents feel free to write things that happened with their child to all of the parents, these are things which did not occur in the past". From A's comments it can be said that the issue of respect for teachers has weakened. Another drawback that the interviewees mentioned was related to nuisance. Many times someone sends a message that does not relate to the entire group but rather to a particular person, like $\mathrm{T}$ commented. "Even regarding the parents, I think it's not right that messages that relate to one person are sent to the whole group, personally this bothers me very much. The WhatsApp is for the group, not everyone is supposed to receive these nonrelevant messages that are not related to them". Another aspect of communicating via WhatsApp is that it is not face to face and lacks expression and emotion as the interviewee $\mathrm{H}$ commented "lack of communication, lack of facial expressions, when a person talks he has facial expressions and feelings that he wants to express. WhatsApp is cold and alienating. It's impossible to express things how you really want to say them. When you see the ah, facial expression when you are talking. Now 
unfortunately, WhatsApp in recent years has become almost the only social connection". From this example one can say that communication via WhatsApp, like any communication that is not face to face, is missing the human characteristics of communication: emotion, facial expressions and body language.

\section{Discussion}

This study examined how the electronic communication, WhatsApp, influences the communication between teachers and parents and the work of the teacher. Analysis of the data revealed three main categories: 1. Management of the group, 2. Content of the WhatsApp 3. The effect of using WhatsApp on the teachers.

\section{Management of the group}

The topic that emerged was the management of the WhatsApp groups. The interviewees indicated that in all groups the teacher opened the initial group and runs the group. Another finding that emerged from the research relates to the issue of limits concerning times and updates via the WhatsApp. Many teachers express concern that as a result of the immediacy and accessibility to the teacher and the information the involvement will turn to intervention, therefore limits should be set using various means and boundaries should be established (Kurtz, 2014). According to Fischer (2010) the issue of limitations that the teacher should set with the parents should be according to the policy of the school and should revolve around agreements that have been built in conjunction with initial expectations. In this research the interviewees suggested limiting the use of WhatsApp to certain times and to emphasize that only the teachers sends the messages.

\section{WhatsApp Content}

The research found that teachers use WhatsApp in order to establish communication with the parents on subjects that are related to technical and essential content. These findings are consistent with the professional literature that sees the new channels of communication as a tool for transmitting information to all the parents, updates and ongoing announcements (Kosaretskii \& Chernyshova, 2013). The interviewees claim that WhatsApp communication allows them to send technical messages or essential announcements. This is similar to what Kurtz (2014) explains that the new channels are used to transmit messages and informal information, which helps parents to participate in school life. 


\section{Effects of the use of WhatsApp on the Teachers}

The research found that communication via WhatsApp has positive but also negative effects on the teacher's work. On the positive side, the interviewees note that the media is available and accessible and all parents receive the message immediately. This central component of the involvement in the frequency of communication that exists between the parents and teacher is raised by Schectman and Boucherian (2015) who point out that the use of new communication media creates new possibilities of communications between parents and teachers mainly because the new channels increase the accessibility of the parent to the teachers. The interviewees stated that in contrast to the communication methods of the past which was passing the message via the students, where the parents did not always receive the message, today it is sent by WhatsApp and everyone is updated immediately. Kurtz (2014) also states that the speed and accessibility of the new media between parents and teachers, are in contrast to the traditional means which are not fast or immediately accessible like the communication notebook. In addition, some of the negative aspects of WhatsApp surfaced. The interviewees stated that the teachers loses control of the messages and sometimes the parents use the group against the teacher. Schectman and Boucherian (2015) also note that sometimes parents can misinterpret the messages sent by the new media. In their words, this is the main obstacle of communication between parents and teachers. As a result of this, parents get angry and drag additional parents into the fray. Thus the teachers experience insult and disrespect from the teachers (Fisher, 2010). Moreover, media channels can be used for negative purposes, such as intentional harm to others while exploiting weaknesses and vulnerabilities (Valkenburg \& Peter, 2011).

In addition, the media removes responsibility of the pupils in the process of learning. The proliferation of messages to parents related to the school part may cause the pupil to remove the burden and responsibility from the learning process. He knows that the teacher will already update what the material is for the test or what the homework is via the WhatsApp and so he can remove from himself the responsibility of being a part of the learning process. Kurtz (2014) also warns that the steady flow of information and updates via the new media causes the removal of responsibility by the pupils for this learning process. The present research shows that the media violates the respect of the teaching staff. The parents' ability to write whatever they think is right leads to the loss of the teacher's status and authority.

Schectman and Boucherian (2015) also point out that the use of new media has implications for neutralizing the callers' status. This means that communication takes place without reference to the social and cultural differences of the communicators, including their place in the social hierarchy. Communication under such conditions "demotes" positions of authority and makes the media a kind of equalizer. As such, it may also lead to a media that has characteristics of conflict and even aggression and insult. An egalitarian communication that is expressed by ignoring the levels of hierarchy may also impair its effectiveness (Shechtman \& Boucherian, 2015). In addition, the research findings indicate that 
sometimes nuisance messages are sent that are not intended for the entire group. Kurtz's (2014) study also found that some parents see the exchange of messages, especially messages sent by the parents to the whole group, unnecessary and bothersome, and do not contribute to everyone.

Finally, the interviewees state that communication via the WhatsApp is devoid of emotion. Without the tone of voice and facial expression it is difficult to understand what the sender meant. When you communicate face to face you can see the speaker, his body language his facial expressions and his tone of voice. But with WhatsApp you are missing all of these (Thompson, 2009). Accordingly, Shechtman and Boucherian (2015) warn that it is important to reiterate that in the eyes of teachers and parents there is no substitute for the continued existence of face-to-face communication channels that allow close contact which creates trust and professional working relationships between parents and educators. Most studies see the development of new communication channels as a positive phenomenon, intended to increase parental involvement but in no way constitutes a substitute for face-to-face communication.

\section{References}

Fischer, Y. (2010). It is possible: Success stories of parent-school partnerships, Tel Aviv: Mofet Institute.

Friedman, Y., \& Fischer, Y. (2002). Identity and Awareness: Fundamentals of parental involvement in school work. Studies of Organization and Administration in Education, 26, 6-33.

Hakyemez, S. (2015). Turkish early childhood educators on parental involvement. European Educational Research Journal, 14(1), 100-112. Doi:https://doi.org/10.1177/1474904114565152

Hamlin, D., \& Flessa, J. (2016). Parental Involvement Initiatives. Educational Policy, (October 19). Doi: https://doi.org/10.1177/0895904816673739

Ho, L., Hung, C., \& Chen, H. (2013). Using theoretical models to examine the acceptance behavior of mobile phone messaging to enhance parent-teacher interactions. $\begin{array}{llll}\text { Computers } & \mathcal{E} & \text { Education, } & \text { 105-114. }\end{array}$ Doi:https://doi.org/10.1016/j.compedu.2012.09.009

Hoover-Dempsey, K.V., Green, C.G., \& Whitaker, M.W. (2010). Motivation and commitment to partnerships for families and schools. In S. L. Christenson \& A. L. Reschly (Eds.), Handbook of School-Family Partnerships (pp. 30-60) New York: Routledge/Taylor and Francis Group.

Jacobson, L. (2003). Phila. Parents to receive marks for 'home support' of students. Education Week, 23, 4.

Jeynes, W. H. (2016). The Relationship between Parental Involvement and African American School Outcomes. Journal of Black Studies, 47(3), 195-216. Doi:https://doi.org/10.1177/0021934715623522

Karapanos, E., Teixeira, P., \& Gouveia, R. (2016). Need fulfillment and experiences on social media: A case on Facebook and WhatsApp. Computers in Human Behavior, 55(b), 888-897. Doi: https://doi.org/10.1016/j.chb.2015.10.015

Keley-Shahin, L., \& Gefen, A. (2014). Alternative Dispute Resolution - Applications in the field of education: Models used in the world and the lessons learned from their operation. Jerusalem: Initiative for Applied Research in Education, Israel Academy of Sciences and Humanities. 
Kosaretskii, S. G., \& Chernyshova, D. (2013). Electronic communication between the school and the home. Russian Education and Society, 55 (10), 81-89. Doi:https://doi.org/10.2753/res1060-9393551006

Kraft, M. A. \& Rogers, T. (2015). The underutilized potential of teacher-to-parent communication: Evidence from a field experiment. Economics of Education Review, 47, 49-63. Doi: https://doi.org/10.1016/j.econedurev.2015.04.001

Kurtz, G. (2014). Use of new communication channels: Collecting data from interested parties teachers and parents, review - as background material for the committee's work, Between School and Family: Teacher-Parent Relations in a Changing Environment. Jerusalem: Initiative for Applied Research in Education.

Olmstead C. (2013). Using technology to increase parent involvement in schools, TechTrends. 57(6), 28-38. Doi: https://doi.org/10.1007/s11528-013-0699-0

Shechtman T., \& Boucherian A. (2015). Between parents and teachers in post-primary education. Jerusalem: Initiative for Applied Research in Education, Israel Academy of Sciences and Humanities.

Starhovsky, R., Hertz-Lazerovitz, R., \& Orland-Barak, L. (2008) Guide for the Perplexed: Windows for guiding teachers, Tel Aviv: Mofet Institute.

Taft, R., Schlein, C., \& Ramsay, C. M. (2016). Parents of Children with Reactive Attachment Disorder: Experiences of School and Family Communications and Interactions. International Journal of Learning, Teaching and Educational Research, 15(1), 66-78.

Thompson, B. (2008). Characteristic of parent-teacher E-mail communication. Communication Education, 57(2), 201-223. Doi: https:/ / doi.org/10.1080/03634520701852050

Thompson, B. (2009). Parent-teacher e-mail strategies at the elementary and secondary levels. Qualitive Research Reports in Communication, 10(1), 17-25. https://doi.org/10.1080/17459430902756203

Valkenburg, P.M., \& Peter, J. (2011). Online communication among adolescents: an integrated model of its attraction, opportunities and risks. Journal of Adolescent Health, 48(2), 121-127. Doi: https://doi.org/10.1016/j.jadohealth.2010.08.020

Witztum, A. (2014). From the book by Yitzchak Gilat 'Only on the internet can I reveal what I am going through' Psychological assistance in an online environment. Dapim, 58, 245-248. 